IP Periodica Polytechnica

Transportation Engineering

47(4), pp. 335-341, 2019

https://doi.org/10.3311/PPtr. 12114

Creative Commons Attribution (i)

RESEARCH ARTICLE

\section{Effect of Fatigue Loading Mode on 718 Alloy Fatigue Properties}

\author{
Juraj Belan ${ }^{1 *}$, Lenka Kuchariková1, Eva Tillová ${ }^{1}$, \\ Denisa Závodská ${ }^{1}$, Mária Chalupová ${ }^{1}$ \\ Received 13 May 2017; accepted 19 February 2018
}

\begin{abstract}
In materials science, fatigue is the progressive and localized structural damage that occurs when a material is subjected to cyclic loading. If the loads are above a certain threshold, microscopic cracks will begin to form at the stress concentrators such as the surface, persistent slip bands (PSBs), interfaces of constituents in the case of composites, and grain interfaces in the case of metals. Eventually a crack will reach a critical size, the crack will propagate suddenly, and the structure will fracture. The first works about fatigue phenomenon were published since 1837 and intensively was investigated by Wöhler in 1860. With needs of using the progressive materials such titanium and Ni-base superalloys become more significant to put under the various fatigue loading these sorts of alloys. Presented article deals with how the various condition of loading influenced an IN718 alloy fatigue lifetime especially. The fatigue tests provided on this kind of material was done via low frequency loading and push-pull or rotation-bending stress up to this time. Fatigue tests of experimental material was carried out at two different frequencies, $20 \mathrm{kHz}$ with stress ration $R=-1$ (push-pull, $\sigma_{m}=0 \mathrm{MPa}$ ) as well as the three-point bending load $R<1\left(\sigma_{\text {om }}=526.8 \mathrm{MPa}\right)$ at low frequency $150 \mathrm{~Hz}$ at room temperature. The microstructure characterization and Scanning Electron Microscopy (SEM) fractography analysis of fatigue process were done as well. The main goal of study was analyze obtained data after fatigue test and consider, if the various loading modes have influence on fatigue lifetime (initiation sites, crack propagation character, etc.).
\end{abstract}

\section{Keywords}

Alloy IN718, fatigue loading, S-N curve, SEM fractography analyzes

\footnotetext{
${ }^{1}$ Department of Materials Engineering,

Faculty of Mechanical Engineering,

University of Žilina,

Univerzitná 8215/1, 01026 Žilina, Slovakia

*Corresponding author, e-mail: juraj.belan@fstroj.uniza.sk
}

\section{Introduction}

The nickel-chromium-iron base superalloy, known as Inconel 718 , is widely used superalloy for over more than 50-years in aerospace industry mainly. It combines excellent creep-rupture life, high strength, and outstanding weldability. All mentioned characteristics predetermine this alloy to use for temperatures up to $700{ }^{\circ} \mathrm{C}$. The microstructure consist of solid solution of elements such $\mathrm{Cr}, \mathrm{Co}$, and $\mathrm{Fe}$ - so called as gamma matrix ( $\gamma$-phase). Moreover, primary MC carbides (mostly crated by elements as $\mathrm{Mo}, \mathrm{Ti}$, and $\mathrm{Nb}$ - particularly in this 718 alloy) which significantly improve creep-rupture properties and are situated at grain boundaries of origin austenitic grains. Due to lesser amount of $\mathrm{Al}$ and $\mathrm{Ti}$ is fine $\mathrm{Ni}_{3} \mathrm{Al}(\mathrm{Ti})$ gamma prime phase ( $\gamma^{\prime}$-phase, coherent hardening phase with face centered cubic $\mathrm{L}_{12}$ lattice) at higher temperatures during solidification presented as well. Higher amount of $\mathrm{Nb}$ (over wt. $4 \%$ in wrought alloys, in some dendritic areas it may rises up to wt. $8 \%$ in cast alloys), which leads to forming of main precipitation hardening phase, especially in 718 alloy, also known as $\mathrm{Ni}_{3} \mathrm{Nb}$ gamma double prime phase ( $\gamma^{\prime \prime}$-phase, crystalize in $\mathrm{DO}_{22}$ body centered tetragonal lattice) (Paulonis et al., 1969; Kirman and Warrington, 1970; Cozar and Pineau, 1973). The $\gamma^{\prime \prime}$ and $\gamma^{\prime}$ phases have unique morphologies. The $\gamma^{\prime}$ phase precipitates as round particles with size less than $200 \AA$, and continues to be round in shape when it coalesces at higher temperatures. The $\gamma^{\prime \prime}$ phase rather takes the shape of a disk with a length of 5 to 6 times its thickness; however, when the $\gamma^{\prime \prime}$ phase precipitates at very low temperatures, a TEM is necessary to resolve its shape. Another phase with the same chemical formula as gamma double prime is delta phase ( $\delta$-phase, $\mathrm{Ni}_{3} \mathrm{Nb}$ is incoherent with the $\gamma$ solid solution, crystalizes in orthorhombic crystal structure). The delta phase is found mostly as plates growing on the (111) planes or nucleating on the grain boundaries, and is associated with loss of strength as well as loss of fatigue lifetime in this alloy (Radavich, 1989).

During the past few decades, extensive investigations have been made on the low cycle fatigue (LCF) and high cycle fatigue (HCF) properties of IN718. For example, the effect of temperature on the cyclic stress-strain response and LCF life associated with the deformation microstructures (Fournier and Pineau, 1977); the factors (temperature, environment and loading parameters, 
etc.) influencing fatigue crack growth (Prakash et al., 2009); the mechanism-based modelling of fatigue life prediction, and so on. However, another study (Masuda and Tanaka, 1986), under ultrasonic frequency, revealed that fatigue fracture of IN718 occurred between $10^{7}$ and $10^{8}$ cycles. As the experimental work suggests, it is still disputable whether this superalloy under practical loading would show VHCF or not. Furthermore, it is known that the fatigue crack initiation process becomes increasingly important with the extension of fatigue life.

In this study, the high cycle fatigue (HCF) tests with two different loading modes were used to achieve fatigue lifetime S-N curve. The first test was carried out at IN718 experimental samples with high-frequency push-pull loading ( $\mathrm{f}=20 \mathrm{kHz}$, $\sigma_{\mathrm{m}}=0 \mathrm{MPa}$ ) and second test was carried out at IN 718 experimental samples with low-frequency three-point bending load ( $\mathrm{f}=150 \mathrm{~Hz}, \sigma_{\mathrm{m}}=-526.8 \mathrm{MPa}$ ). All fatigue tests were provided at room temperature. With the help of scanning electron microscope (SEM), fractography analyses were performed to disclose the fracture features of specimens in different life ranges.

\section{Experimental material and methods}

The experimental material for both fatigue tests was nickel-chromium-iron base superalloy IN718. The chemical composition (wt. \%) is: $\mathrm{C}-0.026$; $\mathrm{Si}-0.09 ; \mathrm{Mn}-0.07$; $\mathrm{P}-0.008$; $\mathrm{S}<0.001 ; \mathrm{Al}-0.57$; B - 0.004; $\mathrm{Bi}(\mathrm{ppm})<0.1 ; \mathrm{Co}-0.14$; $\mathrm{Cr}-19.31 ; \mathrm{Cu}-0.03 ; \mathrm{Mo}-2.99 ; \mathrm{Nb}-5.30 ; \mathrm{Ni}-53.32$; $\mathrm{Pb}(\mathrm{ppm})-0.1 ; \mathrm{Se}(\mathrm{ppm})<3 ; \mathrm{Ta}<0.01 ; \mathrm{Ti}-0.96 ; \mathrm{Ni}+\mathrm{Co}$ $-53.46 ; \mathrm{Nb}+\mathrm{Ta}-5.31$; and $\mathrm{Fe}-$ balance.

The material was heat treated, according to the supplier's BIBUS Ltd. (CZ) material sheet, at $980^{\circ} \mathrm{C} / 1 \mathrm{hr} \mathrm{AC}$ (air cooled) and heating at $720{ }^{\circ} \mathrm{C} / 8 \mathrm{hrs}$ followed FC (furnace cooled) $\left(50{ }^{\circ} \mathrm{C}\right.$ per hour) to temperature $620^{\circ} \mathrm{C}$ holding time $8 \mathrm{hrs}$ and air cooled. The achieved mechanical properties of the material with grain size ASTM 12 are in Table 1.

Table 1 Mechanical properties of INCONEL alloy 718 as received, according to BIBUS Ltd. material sheet

\begin{tabular}{ccccc}
\hline Temp. $\left[{ }^{\circ} \mathrm{C}\right]$ & $\mathrm{R}_{\mathrm{p}} 0.2[\mathrm{MPa}]$ & $\mathrm{R}_{\mathrm{m}}[\mathrm{MPa}]$ & $\begin{array}{c}\text { Elongation } \\
\mathrm{A}[\%]\end{array}$ & $\begin{array}{c}\text { Reduced } \\
\text { area Z }[\%]\end{array}$ \\
\hline 20 & 1213 & 1549 & 21.3 & 33.3 \\
649 & 986 & 1123 & 22.6 & 68.0 \\
Temp. $\left[{ }^{\circ} \mathrm{C}\right]$ & $\mathrm{HBW}$ & $\sigma_{\mathrm{T}} / 649$ & Rupture life & $\mathrm{A}[\%]$ creep \\
20 & $10 / 3000$ & {$[\mathrm{MPa}]$} & {$[\mathrm{hrs}]$} & - \\
649 & 429 & - & - & 45.7 \\
\hline
\end{tabular}

The high frequency fatigue experiments were performed on 10 specimens with hourglass shape, Fig. 1, by ultrasonic pushpull method and appropriate cooling was used to avoid the temperature rise. Experimental fatigue machine KAUP - ŽU with loading frequency $20 \mathrm{kHz}$ was developed by Department of Material Science, Faculty of Mechanical Engineering,

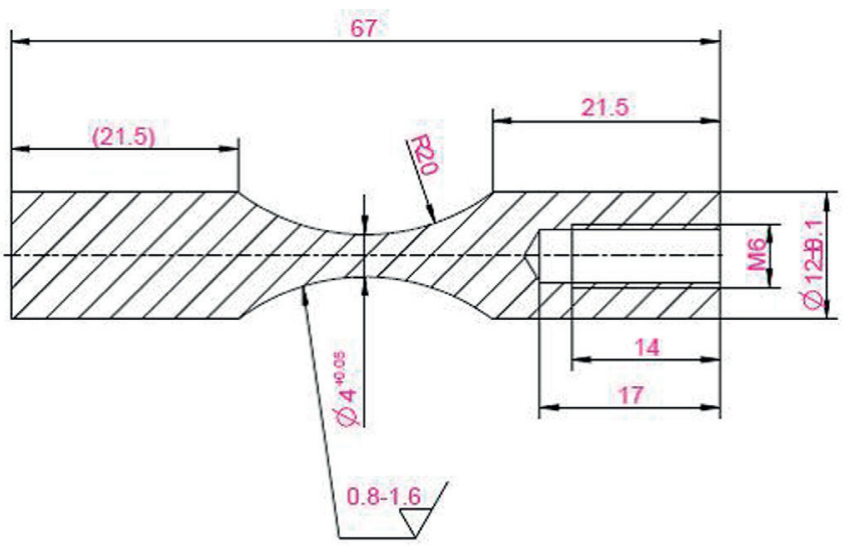

Fig. 1 Specimen for high frequency fatigue testing - hourglass shape, with used dimensions in $\mathrm{mm}$.

University of Žilina in Slovak Republic. Stress ratio of $\mathrm{R}=-1$ was used for experiments.

The three point flexure fatigue test was carried out on testing machine ZWICK/ROELL Amsler 150 HFP 5100 at room temperature with a static pre-load $\mathrm{F}_{\text {static }}=-15 \mathrm{kN}$ (this value may be considered as $\mathrm{F}_{\text {medium }}$ when dynamic load changes from maximum to minimum around this $\mathrm{F}_{\text {medium }}$ ) and dynamic force $\mathrm{F}_{\text {dynamic }}$ varies from $6.31 \mathrm{kN}$ up to $12.8 \mathrm{kN}$. The value of $2.10^{7}$ cycles was set as a reference and when the sample had reached this value without breaking, the so-called run-out, that bending stress was considered as the fatigue lifetime limit. The frequency of fatigue tests was approximately $f=150 \mathrm{~Hz}$. Shape of testing specimens (for experiment were 10 specimens used) was similar as for Charpy's impact toughness test with dimensions $10 \mathrm{~mm}$ x $11 \mathrm{~mm}$ x $55 \mathrm{~mm}$; of course with no notch. Test and specimen settlement is shown on Fig. 2.

Equation (1) was used for the calculation of the maximum bending stress:

$$
\sigma_{O \max }=\frac{3 \times F \times L}{2 \times b \times h^{2}} \quad[M P a]
$$

where $\sigma_{\text {omax }}$ is the maximum bending stress / $\mathrm{MPa}, F$ is the dynamic load / N, $L$ is the distance of supports / mm, $b$ and $h$ are the specimens width and height $/ \mathrm{mm}$.
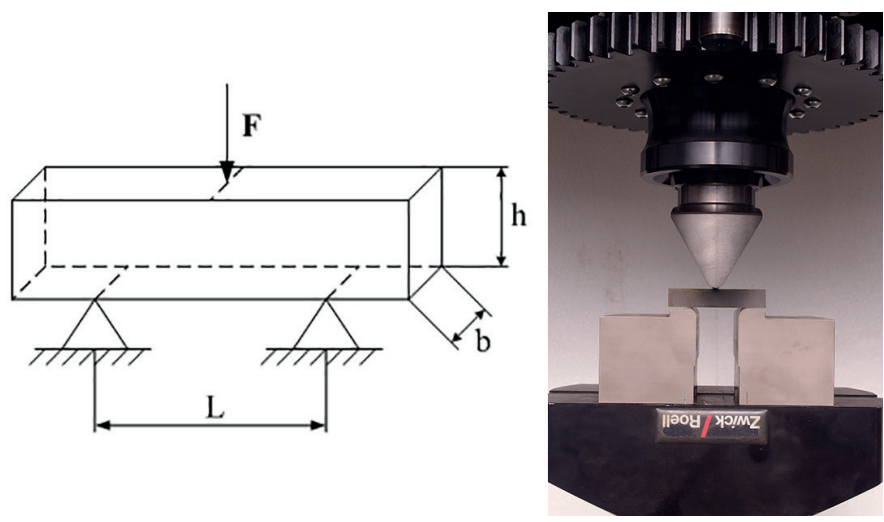

Fig. 2 Schematic drawing for maximum bending stress calculation and specimen settlement at the three-point flexure fatigue test. 
For fractography analysis we used the scanning electron microscope TESCAN Vega II LMU. The fractographic analysis was done in order to describe micro-mechanisms of fatigue crack initiation, fatigue crack propagation (FCP) and final static fracture of specimens.

\section{Results and discussion}

The starting microstructure of experimental specimens was formed by solid solution $\gamma$, with matrix incoherent $\mathrm{Ni}_{3} \mathrm{Nb} \delta$-phase, and primary $\mathrm{MC}(\mathrm{NbC}$ or $\mathrm{TiC})$ carbides, Fig. 3, as were mentioned above. The main hardening $\gamma^{\prime \prime}$-phase is at this magnification and observation method not visible. The grain size according the ASTM standard is $n=12$ (it means average diameter of 5.6 $\mu \mathrm{m}$ (ASTM E112-96)). The microstructure of starting stage is also characterized with deformation twins. The incoherent $\delta$-phase is presented in two fundamental morphologies; quasi-globular or blocky shape and needle-like morphology. Light grey blocky shape $\delta$-phase is mostly situated inside of primary gamma grains, while needle-like $\delta$-phase is presented mostly at grain boundaries. In both forms, the $\delta$-phase has positive influence on grain boundary size and strength stability. However, at higher volume is for mechanical properties its presence detrimental.

To observe $\gamma^{\prime \prime}$-phase, its morphology, the TEM observation techniques were employed, Fig. 4. Fig. 4a confirms the fact about disc-like morphology of $\gamma^{\prime \prime}$-phase. Fig. $4 \mathrm{~b}$ documents the one of the common way of $\delta$-phase morphology, in blocky form, with $\gamma^{\prime \prime}$-phase depleted area around the $\delta$-phase due to higher volume of $\mathrm{Nb}$ content presented in $\delta$-phase rather to form $\gamma^{\prime \prime}$-phase.

The whole fatigue process, of high-strength materials containing non-metallic inclusions can be described in a multistage Wöhler-type S-N curve, Fig. 5.

Zone I corresponds to the fatigue also known as LCF (Low Cycle Fatigue) that is defined with a small number of cycles (about $10^{5}$ cycles). It is characterized by testing in high stress amplitudes and fatigue failure initiates mostly at the surface.

Zone II is zone of limited endurance which is generally between $10^{5}$ and $10^{7}$ cycles. This is the fatigue area of many cycles (HCF - High Cycle Fatigue). It is noted that in this area a lower loading involves a greater number of cycles to failure (Nf).

Zone III shows the fatigue having very large number of cycles (for the number of higher than $10^{7}$ cycles). In this zone fatigue failures occur at stresses below the conventional $\mathrm{HCF}$ fatigue limit, originating in most cases from internal defects.

Zone IV shows a case corresponding to a material that continues to damage, even at lower stresses, whereas the other two cases show that the material has reached a stress below which microstructural mechanisms are perfectly reversible or their irreversibility would be negligible (Mughrabi, 2006).

From fatigue tests were plotted the S-N curves, Figs. 6, 7.

Fig. 8, which is combination of Figs. 6 and 7 for better comparison, how the different modes of fatigue loading have influence on fatigue lifetime. We expect some differences due to

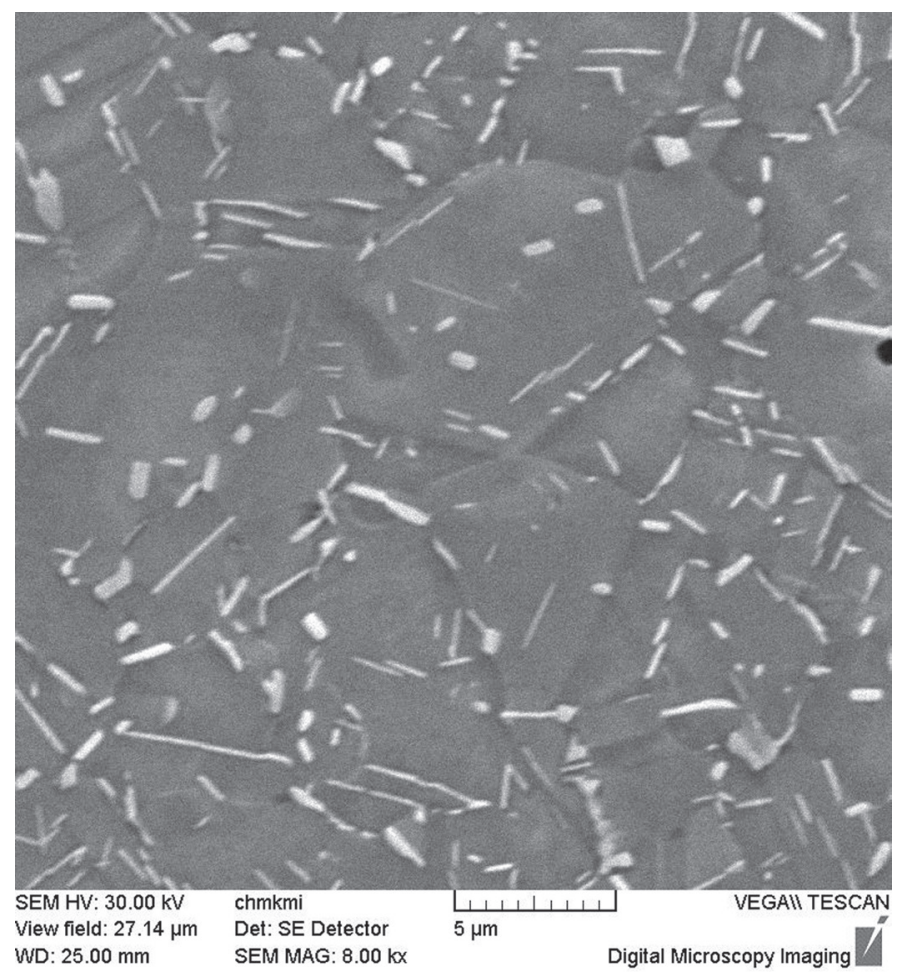

a)

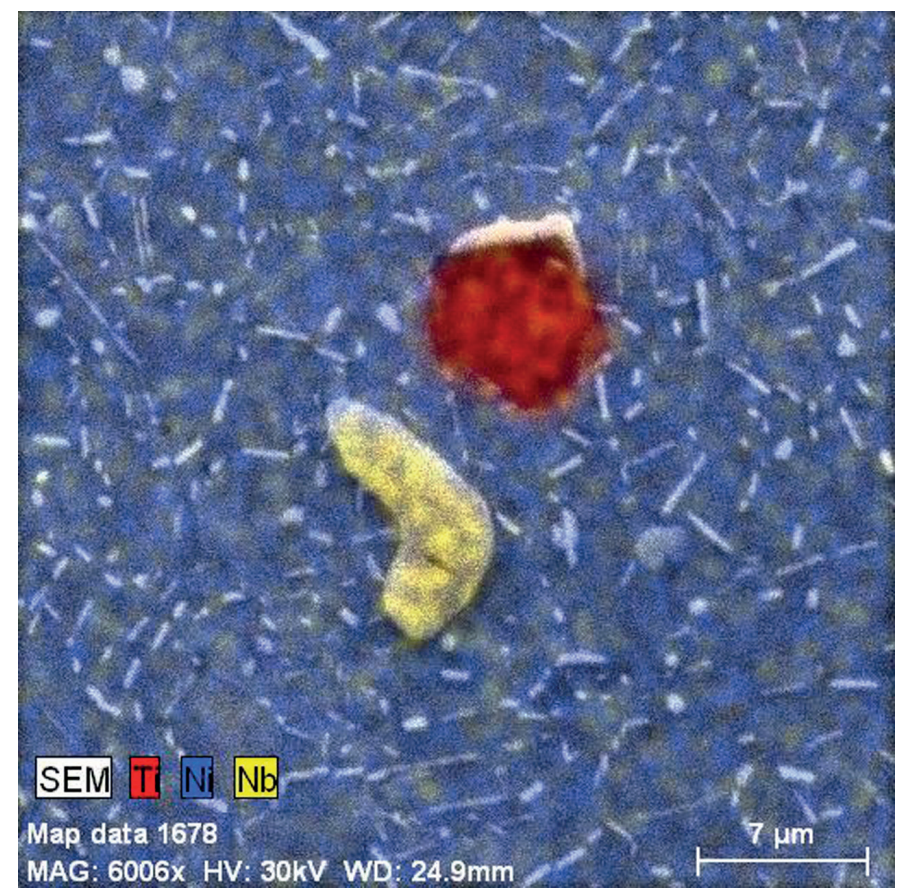

b)

Fig. 3 Microstructure of wrought alloy as seen in SEM and the MC carbides in INCONEL alloy 718 and SEM mapping, etched Kallings

different loading modes. At push-pull loading there is constant normalized stress equal to chosen amplitude, and medium stress is equal to zero, $\sigma_{\mathrm{m}}=0 \mathrm{MPa}$. At three-point flexure loading we need to use $\sigma_{\mathrm{m}}=613 \mathrm{MPa}$ what means that specimens were loading with this value and dynamic amplitude vary.

Results obtained at push-pull and three-point bending loading were approximated with Eq. (2) for the push-pull fatigue loading and Eq. (3) for three-point bending fatigue loading 


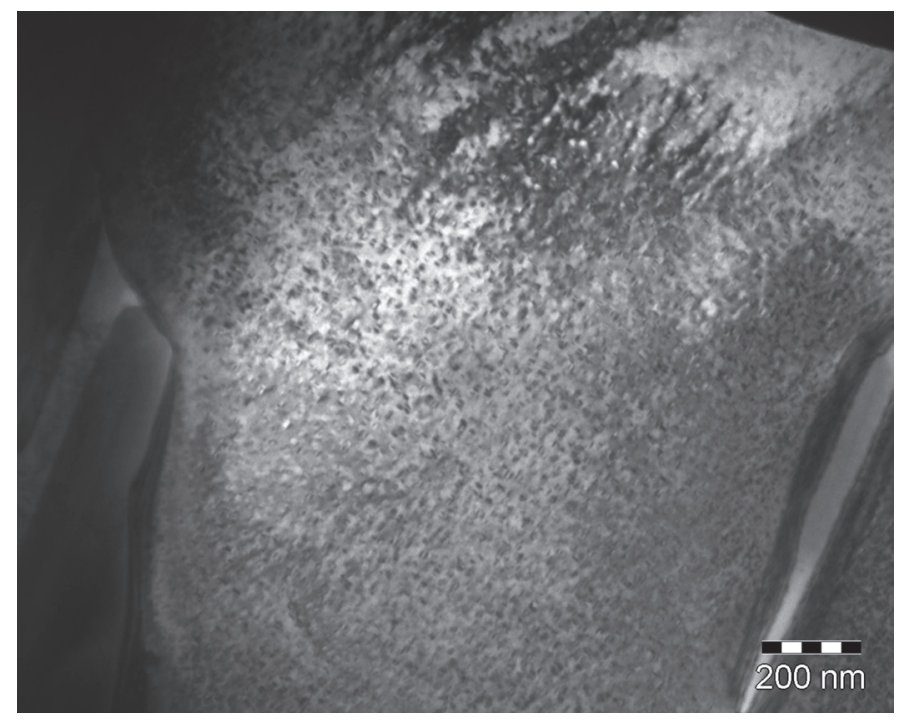

a)

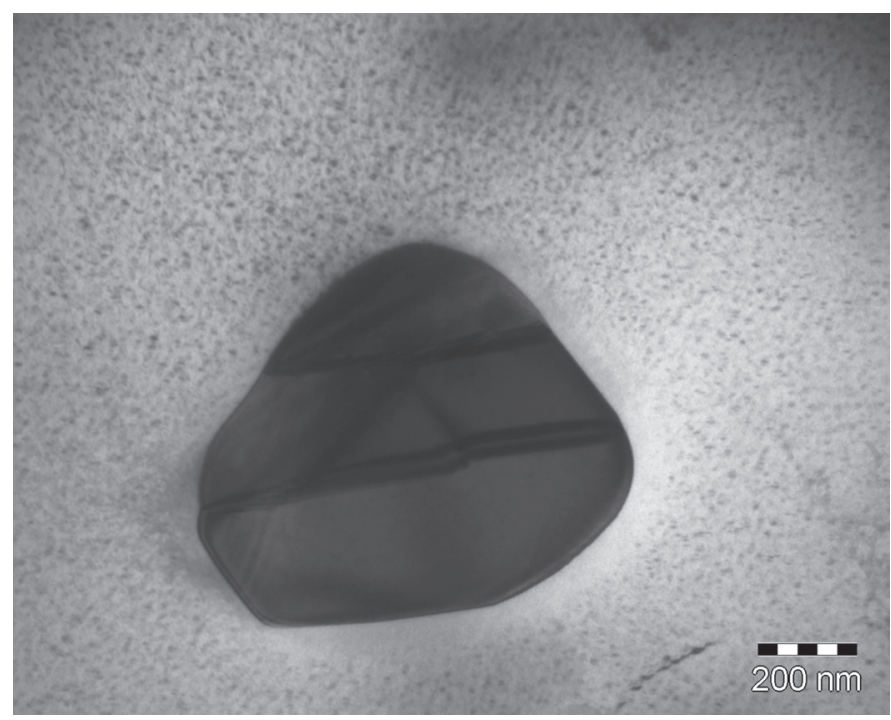

b)

Fig. 4 Micrographs of wrought alloy with using of TEM; a) disc-like morphology of main strengthening $\gamma^{\prime \prime}$-phase;

b) blocky shape $\delta$-phase with $\gamma$ "-phase depletion

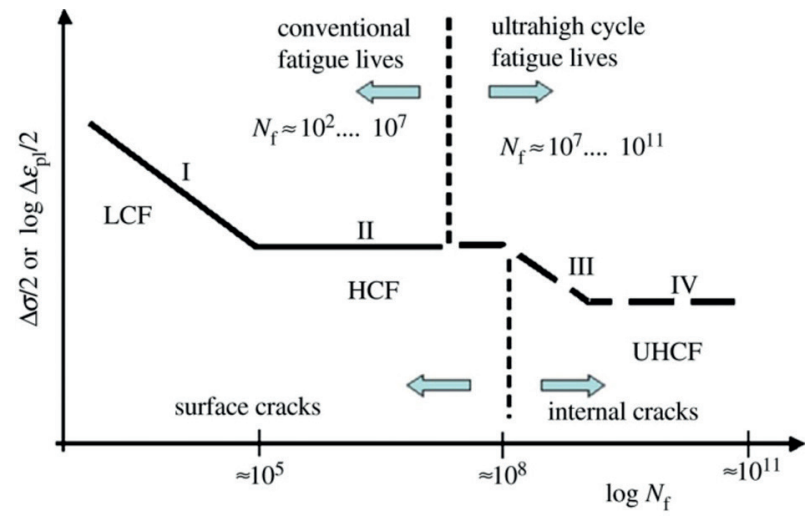

Fig. 5 Schematic fatigue life diagram for materials containing inclusions

what is a Basquin formula for S-N presentation and approximation. This approach was also used at different material (Trško et al., 2013).

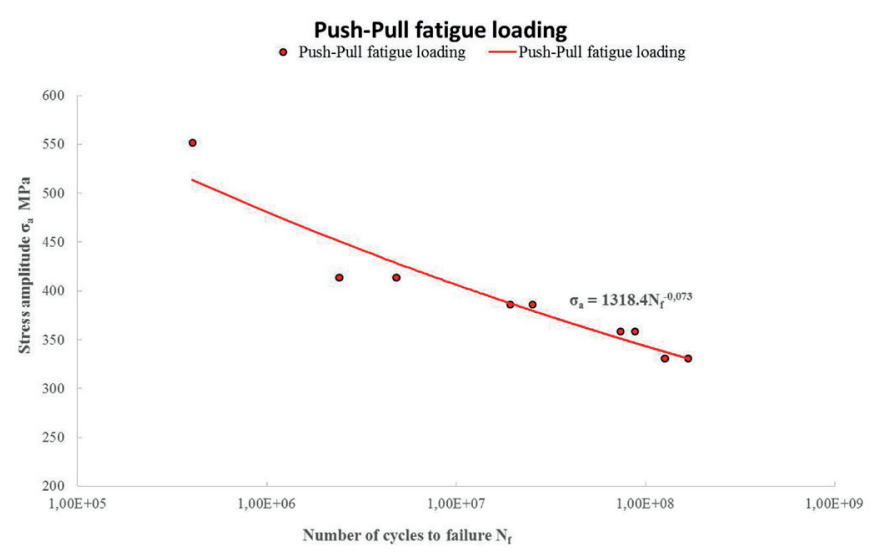

Fig. 6 The S-N curve for ultrasonic push-pull fatigue loading

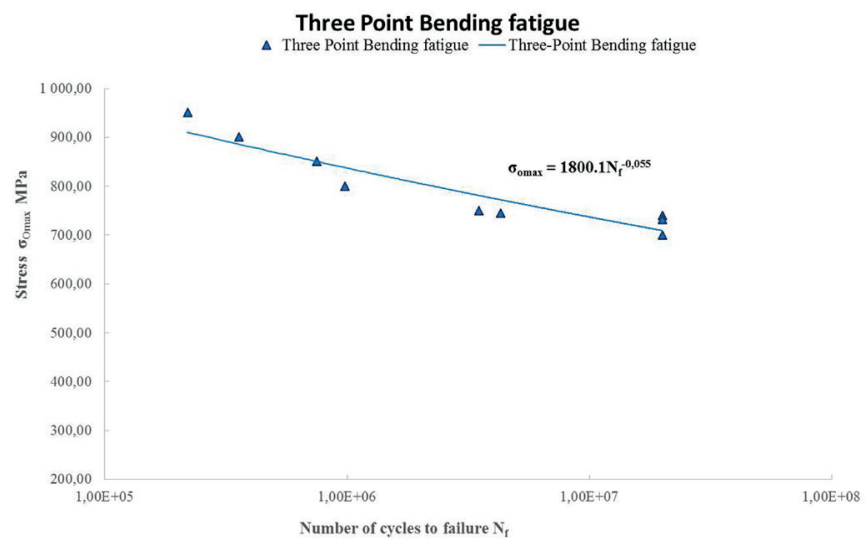

Fig. 7 The S-N curve of three-point flexure fatigue loading

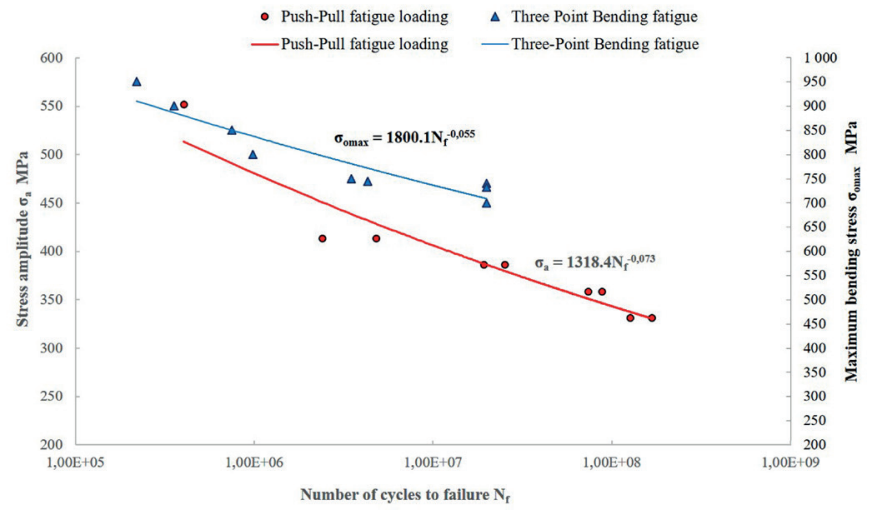

Fig. 8 The S-N curves, results after push-pull fatigue test and three-point bending fatigue test, and its mutual comparison

Push-Pull fatigue loading:

$$
\sigma_{a}=1318.4 \times N_{f}^{-0.073} .
$$

Three-Point Bending fatigue loading:

$$
\sigma_{o \max }=1800.1 \times N_{f}^{-0.055}
$$

where $\sigma_{\mathrm{f}}^{\prime}=1318.4(1800.1)$ is a coefficient of fatigue strength, $\mathrm{N}_{\mathrm{f}}$ is number of cycles to failure, and $-0.073(-0.055)=\mathrm{b}$ is lifetime curve exponent. 
From measured S-N curve is clearly seen that the fatigue life increases with decreasing stress amplitude and the $S-N$ curve appears to continuously decline as the life extends. Note that fatigue failure of this superalloy continues to occur after exceeding $10^{7}$ cycles what is value considered as a fatigue limit for most of steels and hard materials. The longest fatigue life of the fractured specimens is $1.679 \times 10^{8}$ cycles, which takes 2 hours and 19 minutes of fatigue testing at frequency of 20.13 $\mathrm{kHz}$ and the stress amplitude was $\sigma_{\mathrm{a}}=386 \mathrm{MPa}$. The test result can be regarded as the direct evidence of fact that IN718 may still fracture in the VHCF regime at room temperature.

The limit number of cycles at three-point bending $-2 \times 10^{7}$ (20 000078 ) - was reached at the maximum bending stress $\sigma_{\text {omax }}=740 \mathrm{MPa}$. Accordingly, fatigue lifetime stress obtained using a different testing method - ultrasonic push-pull loading with $R=-1$ (Belan, 2015; Vaško et al., 2015; Vaško and Vaško, 2014) - increases this factor by two fold higher (pushpull fatigue lifetime of about $386 \mathrm{MPa}$ compared to threepoint flexure fatigue lifetime of $740 \mathrm{MPa}$ at the same number of cycles). Of course, these values may only roughly be compared because of different frequency of test and different mechanisms of loading.

A fractography results are presented on Figs. 9 and 11. Figs. 9a and $9 \mathrm{~b}$ show the initiation sites (marked by arrows). At higher amplitudes note the multiple initiation sites. In this case, the major crack is created by several minor cracks originated

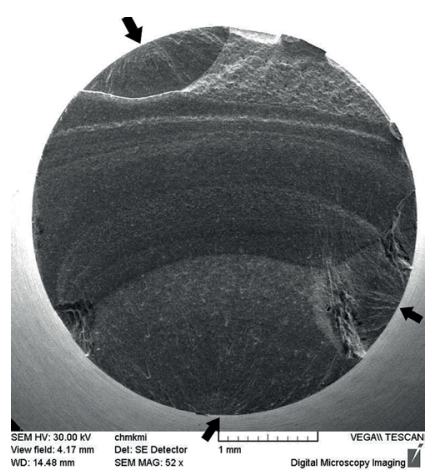

a)

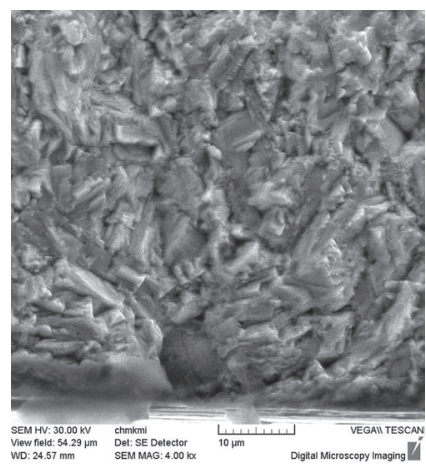

c)

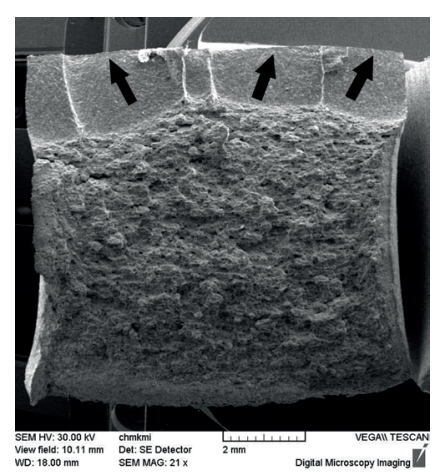

b)

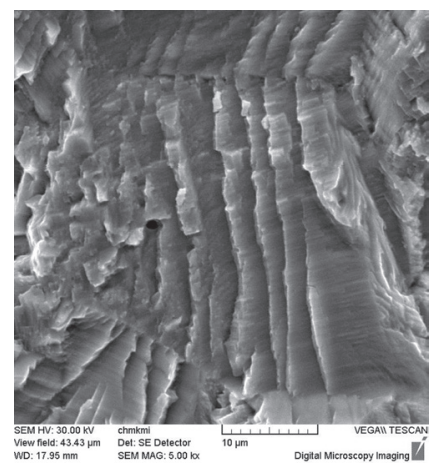

d)
Fig. 9 Fractography observation of samples after push-pull fatigue loading 7a, $\mathrm{c}$; and after three-point bending fatigue test $7 \mathrm{~b}, \mathrm{~d}$. Initiation sites of fatigue cracks are marked by arrows. from multiple initiation sites and creates macroscopic fluctuant fracture surface. When stress level is reduced the initiation comes only from single site what lead to less surface roughness.

There are two different modes of fatigue crack initiation depending on stress amplitude level. At higher stress amplitude levels, fatigue crack initiate at the surface from the persistent slip bands (PSB - reason of cyclic loading, Fig. 10a (Milella, 2013)). This initiation mechanism occurs especially at high cycle fatigue (HCF) loading. The second initiation mechanism is so called "fish-eye" observed when stress amplitude level is lower. In this case, the initiation site is a non-metallic inclusion situated under surface, Fig. 10b (Bathias and Paris 2005), mostly presented at giga-cycle fatigue (GCF) loading. In our case the initiation goes via PSB at the specimen's surface as a relatively flat cleavage fracture surface, when in push-pull loading on rounded specimens initiation runs from the cracked carbide particle near to surface, Fig. 9c; in the case of three-point flexure loading the initiation originates as cleavage fracture steps with plastic striation - kind of mixed mechanism, Fig. 9d.

Careful examination reveals that crack nucleation and propagation in the early state of deformation occur preferentially along slip bands. Crack nucleation can also form from carbides precipitating during the cyclic loading; the carbide precipitates are continuously generating some discontinuity at the interface between slip bands and carbide precipitates and at the location of carbide precipitates within the grain boundaries, Fig. 9c.

After initiation process is fatigue process characterized by fatigue crack propagation with transcrystalline mechanism with fine striation and secondary crack, Figs. 11a and 11b. As the number of cycles increases a mixed mode of cleavage and quasi cleavage like fractures becomes more pronounced especially after the cracks extend over several grains in depth and become predominant with the advance of crack length (brittle fracture zone), Fig. 11a. Striations can be increasingly observed as the crack propagates stably with increasing fatigue loading cycles as indicated in Fig. 11b. Striations grow coarser and their separation is more distinct. These classical striation

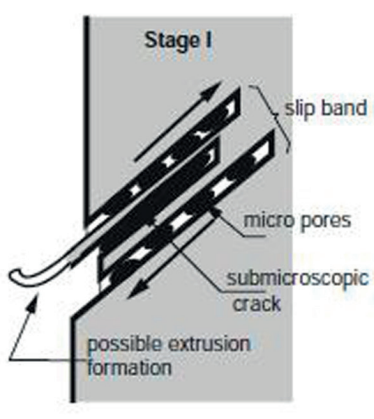

a)

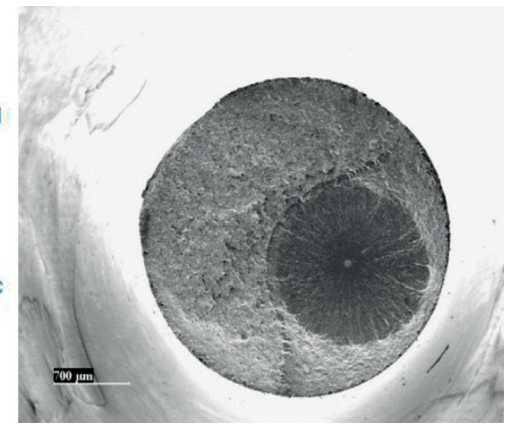

b)
Fig. 10 Two different fatigue crack initiation mechanism, so called "Persistent Slip Bands (PSB)" at higher stress amplitude levels and HCF (a); and so called "fish-eye" initiation on inclusion under surface at lower stress amplitude and GCF 


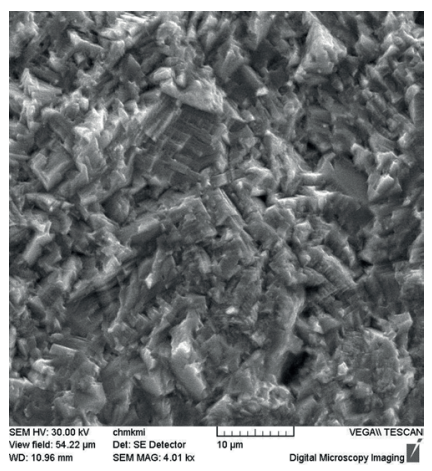

a)

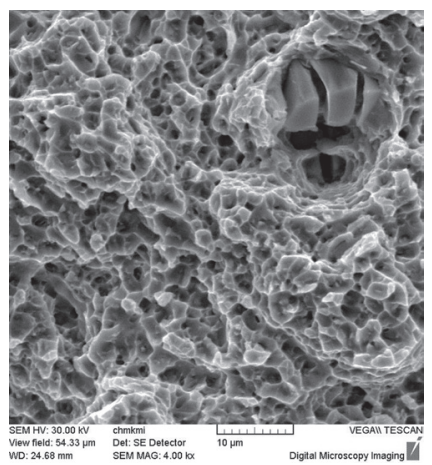

c)

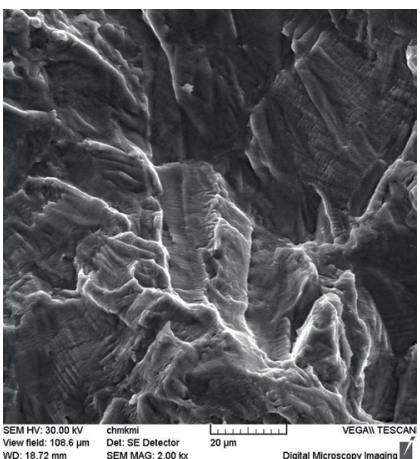

b)

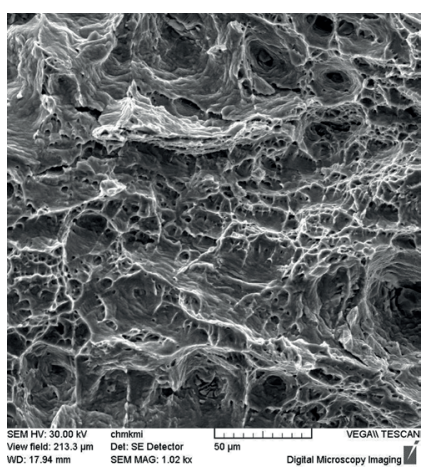

d)
Fig. 11 Fractography observation of samples after push-pull fatigue loading 9a, c; and after three-point bending fatigue test $9 \mathrm{~b}, \mathrm{~d}$.

morphologies indicate increasing levels of plasticity. Some striations are associated with secondary crack branches Fig.11b. It is clear that the fracture surface tends to become more ductile and softening with increasing number of cycles to failure. Some of this tendency may be due to the increasing interactions between carbide precipitates and slip deformation bands with the cyclic loading. These interactions promote the shearing of carbide precipitates and, as a consequence, the development of many more discontinuity regions where striation and slip deformation easily nucleate and grow (Mohamed, 2014).

The last two Figs. 11c and 11d represent the static fracture area of both push-pull and three-point bending fatigue loading. This last stadium of fatigue process is typical for ductile dimpled fracture mechanism, in some cases also characterized with fracture of primary $\mathrm{NbC}$ carbides, Fig. 11c.

\section{Conclusions}

The nickel-chromium-iron base superalloy IN718 was used for two different fatigue tests with aim to find out how the pushpull or three-point bending loading affecting the fatigue lifetime. From obtained result we can formulate following conclusions:

- At higher volume of loading amplitude the fatigue crack initiate from multiple sources situated at the specimens surface.

- No matter what kind of loading is used, stable fatigue crack propagation is driven by transcrystalline mechanism with fine striation and very fine secondary crack.
Final stage, static failure is characteristic by ductile dimple fracture mechanism.

Comparing results of fatigue test is clear to see, that fatigue limit or fatigue lifetime is as much two times lower at pushpull loading $\left(\sigma_{\mathrm{m}}=386 \mathrm{MPa}\right)$ compared to three-point bending loading $\left(\sigma_{\text {omax }}=740 \mathrm{MPa}\right)$. It is important from practice point of view and needs to be payed attention at mechanical parts design an applied loading on such parts.

\section{Acknowledgement}

The project presented in this article is supported by Scientific Grant Agency of Ministry of Education of The Slovak Republic and the Slovak Academy of Sciences, No. 1/0533/15, No. 049ŽU-4/2017 and project EU ITMS 26220220154.

\section{References}

ASTM E112-96 (2004). Standard Test Methods for Determining Average Grain Size. ASTM International, West Conshohocken, PA, USA.

Bathias, C, Paris, P. C. (2005). Gigacycle Fatigue in Mechanical Practice. Marcel Dekker, New York, USA.

Belan, J. (2015). High frequency fatigue test of in 718 alloy - microstructure and fractography evaluation. Metalurgija - Metallurgy. 54(1), pp. 59-62.

Cozar, R., Pineau, A. (1973). Morphology of y' and y" precipitates and thermal stability of inconel 718 type alloys. Metallurgical and Materials Transactions B. 4(1), pp. 47-59.

Fournier, D., Pineau, A. (1977). Low cycle fatigue behavior of inconel 718 at $298 \mathrm{~K}$ and $823 \mathrm{~K}$. Metallurgical and Materials Transactions A. 7(8), pp. $1095-1105$

Kirman, I., Warrington, D., H. (1970). The precipitation of $\mathrm{Ni}_{3} \mathrm{Nb}$ phases in a $\mathrm{Ni}-\mathrm{Fe}-\mathrm{Cr}-\mathrm{Nb}$ alloy. Metallurgical and Materials Transactions B. 1(10), pp. 2667-2675.

Masuda, C., Tanaka, Y. (1986). Relationship between fatigue strength and hardness for high strength steels. Nippon Kikai Gakkai Ronbunshu, A Hen/Transaction of the Japan Society of Mechnical Engineers, Part A. 52(476), pp. 847-852.

Milella, P. P. (2013). Fatigue and Corrosion in Metals. Springer-Verlag Italia, Milano, Italia. https://doi.org/10.1007/978-88-470-2336-9

Mohamed, A. (2014). Fractographic Characterization Of INCONEL 601. International Journal of Engineering Research and Applications. 4(5), pp. 154-158.

Mughrabi, H. (2006). Specific features and mechanisms of fatigue in the ultrahigh-cycle regime. International Journal of Fatigue. 28(11), pp. 15011508.

Paulonis, D. F., Oblak, J. M., Duvall, D. S. (1969). Precipitation in nickel-base alloy 718. Transactions of American Society for Metals (ASM). 62(3), pp. 611-622.

Prakash, D. G. L., Walsh, M. J., Maclachlan, D. W., Korsunsky, A. M. (2009). Crack growth micro-mechanisms in the IN718 alloy under the combined influence of fatigue, creep and oxidation. International Journal of Fatigue. 31(11-12), pp. 1966-1977.

Radavich, J. F. (1989). The Physical Metallurgy of Cast and Wrought Alloy 718. In: Superalloy 718 - Metallurgy and Applications. (Loria, E. A. (ed.)) The Minerals, Metals \& Materials Society (TMS), Pennsylvania, USA.

Trško, L., Bokůvka, O., Guagliano, M., Nový, F., Hazlinger, M. (2013). U1tra-long fatigue life of 50CrMo4 steel with strengthened surface by high 
energy shot peening. In: Proceedings - 30th Danubia-Adria Symposium on Advances in Experimental Mechanics. (Alfredic, I., Semenski, D. (eds.)) Croatian Society of Mechanics, Zagreb, Croatia.

Vaško, A., Trško, L., Konečná, R. (2015). Fatigue behavior of synthetic nodular cast irons. Metalurgija - Metallurgy. 54(1), pp. 19-22.

Vaško, M., Vaško, A. (2014). Correlation between Charge Composition and Fatigue Properties of Nodular Cast Irons. Applied Mechanics and Materials. 474, pp. 291-296. 